\title{
Efektivitas Sosiodrama dalam Meningkatkan Kepedulian Sosial di Sekolah Dasar
}

\author{
Kardiana Metha Rozhana ${ }^{1}$, Nila Kartika Sari \\ PGSD FIP Universitas Tribhuwana Tunggadewi \\ E-mail: jr.kardiana@yahoo.com
}

\begin{abstract}
Abstrak
Tujuan penelitian untuk mengetahui dan membuktikan sosiodrama efektik dalam meningkatkan kesadaran kepedulian sosial di sekolah dasar. Penelitian menggunakan eksperimental semu. Rancangan penelitian yang digunakan adalah pretest dan postest satu kelompok (the one group pretest - posttest design). Rancangan penelitian ini, satu kelompok tes atau subyek penelitian akan diberikan treatment yang sama. Treatment yang diberikan adalah sosiodrama yang dapat meningkatkan kepedulian sosial. Secara signifikansi berdasarkan pengujian hipotesis, yaitu uji beda two related samples test Wilcoxon diperoleh nilai Wilcoxon sebesar $\left(Z^{=}-4.783^{\mathrm{a}}\right)$ dengan nilai asymp.Sig (2-tailed) sebesar 0.000. Hal ini dapat disimpulkan bahwa terjadi perbedaan tingkat yang signifikan pada kepedulian sosial siswa antara sebelum dan sesudah melakukan pelatihan sosiodrama pada sasaran eksperimen. Hal ini dibuktikan dengan nilai asymp.Sig (2-tailed) lebih kecil dari 0.05 atau probability error $\left(P^{=} 0.000<0.05\right)$. dengan kata lain bahwa teknik sosiodrama efektif untuk meningkatkan kepedulian sosial siswa sekolah dasar. Maka dapat disimpulkan bahwa, terdapat perbedaan yang signifikan antara tingkat kepedulian sosial siswa sebelum dan sesudah diberikan treatment dan teknik sosiodrama efektif untuk meningkatkan kepedulian sosial siswa.
\end{abstract}

Kata kunci: sosiodrama, kepedulian sosial, sekolah dasar

\begin{abstract}
The purpose of the research is to find out and prove the effectiveness of sociodrama in raising awareness of social awareness in primary school. Research using quasi experimental. The research design used was the pretest and posttest one group (the one group pretest - posttest design). The design of this study, a group of tests or research subjects will be given the same treatment. Treatment given is sociodrama that can increase social awareness. Significantly based on hypothesis testing, the test of two different samples test Wilcoxon obtained Wilcoxon value of $\left(Z^{=}-4.783^{\mathrm{a}}\right)$ with asymp.Sig (2-tailed) value of 0.000 . It can be concluded that there is a significant difference in the level of social awareness among students before and after conducting sociodrama training on experimental targets. This is evidenced by the asymp.Sig (2-tailed) value smaller than 0.05 or probability error $\left(P^{=} 0.000<0.05\right)$.. in other words that the sociodrama technique is effective to improve the social awareness of elementary school students. So it can be concluded that, there is a significant difference between the level of social awareness of students before and after being given effective treatment and sociodrama techniques to improve students' social awareness.
\end{abstract}

Keywords: sociodrama, social concern, elementary school 


\section{INTELIGENSI: Jurnal Ilmu Pendidikan 2018 -1}

\section{PENDAHULUAN}

Pendidikan karakter saat ini sedang gencar dilaksanakan diberbagai kalangan sekolah. Tujuannya yaitu untuk membentuk moral yang positif. Saat ini moral masyarakat sudah berada di tahap kritis. Banyak sekali perilaku negative yang muncul dipermukaan, bahkan siswa yang duduk di bangku sekolah dasar mulai memperlihatkan perilaku negative. Contohnya saja siswa SD sudah tahu pacaran, merokok, dan bullying. Perilaku bullying merupakan salah satu perilaku negative yang menyudutkan pihak lain sehingga akan mengakibatkan kriminalitas, bahkan efek yang ditimbulkan sangat tidak baik untuk korba. Perilaku seperti inilah yang harus diminimalisir di era modern saat ini.

Pendidikan karakter merupakan usaha yang dilakukan untuk mengembangkan karakter poitif berlandaskan suatu kebijakan yang secara keseluruhan dirasa baik bagi individu maupun masyarakat lain. Melalui pendidikan karakter diharapkan perilau bullying dapat diminimalisir sehingga tercipta kepedulian social di lingkungan sekitar. Lingkungan yang dimaksud adalah lingkungan keluarga, lingkungan sekolah, dan lingkungan masyarakat. Karena di lingkungan inilah seseorang mendapat nilainilai tentang kepedulian sosial.

Peran aktif orang tua sangat penting mengingat usia anak sekolah dasar merupakan usia rentang masuknya pengaruh negative dari luar. Proses modernisasi membuat banyak mengalami perubahan fundamental. Hal ini bisa terjadi ketika orang tua yang terlalu sibuk dengan urusan pekerjaan, sehingga mereka tidak begitu mengetahui sejauh mana tingkat perkembangan anaknya. Pada dasarnya perhatian dan pantauan dari orang tua sangat dibutuhkan dalam pembentukan karakter seorang anak agar anak bisa mencapai tugas perkembangan dengan optimal (Lickona, dalam Saptono, 2011:23).

Upaya yang dapat dilakukan untuk meningkatkan kepedulian sosial adalah pendidikan dan pembelajaran hendaknya diperbaiki dengan tidak hanya mengembangkan aspek pribadi namun juga mengembangkan aspek-aspek sosial. Pengembangan aspek-aspek sosial tersebut bisa diperoleh dari salah satu teknik role play (permainan peran) pada pembelajaran. Menurut Romlah (2013) sosiodrama adalah permainan peranan yang ditujukan untuk memecahkan masalah sosial yang timbul dalam hubungan antar manusia. Sosiodrama merupakan dramatisasi dari berbagai persoalan yang dapat timbul dalam pergaulan dengan orang lain, termasuk konflik yang sering dialami dalam pergaulan sosial (Hartinah, 2009:164).

Konflik-konflik sosial yang disosiodramakan adalah konflik-konflik yang tidak mendalam yang tidak menyangkutgangguan kepribadian. Misalnya, pertentangan antar kelompok sebaya, perbedaan individu dengan nilai lingkungan, perbedaan nilai antara anak dengan orang tua, dan sebagainya. Sosiodrama lebih merupakan kegiatan yang bertujuan untuk mendidik atau mendidik kembali daripada kegiatan penyembuhan. Berdasarkan permasalan di atas disusunlah penelitian dengan judul "Efektivitas Teknik Sosiodrama untuk Meningkatkan Kepedulian sosial pada Siswa Sekolah Dasar.

\section{METODE}

Penelitian ini merupakan penelitian eksperimental semu karena persyaratan dalam penelitian eksperimental ini tidak terpenuhi secara sempurna. Persyaratan yang dimaksud adalah kelompok kontrol. Rancangan penelitian yang digunakan adalah pretest dan postest satu kelompok 


\section{INTELIGENSI: Jurnal Ilmu Pendidikan $\mid$ 2018-1}

(the one group pretest - posttest design). dalam rancangan penelitian ini, satu kelompok tes atau subyek penelitian akan diberikan treatment yang sama. Treatment yang diberikan adalah sosiodrama yang dapat meningkatkan kepedulian sosial.

Sugiyono (2011:75) menggambarkan rancangan penelitian sebagai berikut:

$$
\mathrm{O}_{1} \mathrm{XO}_{2}
$$

$\mathrm{O}_{1}=$ nilai pretest (sebelum diberikan perlakuan)

$\mathrm{X}=$ perlakuan/treatment (dengan menggunakan Teknik sosiodrama)

$\mathrm{O}_{2}=$ nilai posttest (setelah diberikan perlakuan)

\section{Keterangan:}

T1 : Pretest (pengukuran awal)

$\mathrm{X}$ : Perlakuan berupa pemberian layanan bimbingan kelompok dengan teknik sosiodrama

T2 : Posttest (pengukuran akhir)

Pengukuran awal atau pretest dilakukan sebanyak satu kali pertemuan. Demikian juga untuk posttest dilaksanakan sebanyak satu kali pada pertemuan terakhir setelah semua rangkaian treatment selesai dilaksanakan.

Populasi adalah wilayah generalisasi yang terdiri atas obyek/ subyek yang mempunyai kualitas dan karakteristik tertentu yang ditetapkan oleh peneliti untuk dipelajari dan kemudian ditarik kesimpulannya (Sugiyono, 2013:117). Populasi dalam penelitian ini yaitu siswa kelas IV SDN 2 Pringapus Kecamatan Dongko Kabupaten Trenggalek. Sedangkan Sampel yaitu semua subjek penelitian semua siswa kelas IV yang terdiri dari 30 siswa. Peneliti menggunakan teknik pengambilan sampel dengan melihat atau merujuk pada tujuan awal yang kemudian diberikannya treatment (perlakuan). Sugiyono (2013 : 124) menyebutkan bahwa sampling jenuh adalah teknik penentuan sampelbila semua anggota populasi digunakan sebagai sampel. Hal ini dilakukan karena jumlah populasi yang relatif kecil.

Siswa yang dijadikan sampel dalam penelitian ini tidak hanya siswa yang memiliki tingkat kepedulian sosial rendah. Pengambilan seluruh populasi siswa kelas IV SD ini didasarkan pertimbangan setiap siswa memiliki tingkat kepedulian sosial yang berbeda-beda dan semua dapat ditingkatkan. Prosedur penelitian yaitu: (persiapan penelitian dengan observasi awal di kelas IV SD di sesuaikan dengan Tema pembelajaran yang terdapat materi peduli terhadap lingkungan social) dan menyusun pelaksanaan penelitian, Pelaksanaan penelitian beripa memberikan pretest, melakukan perlakuan sosiodrama, memberikan posttest setelah diberi perlakuan, menganalisis hasil pretest dan posttest dengan uji beda rata-rata dua sampel berpasangan (paired samples T Test).

Instrumen penelitian adalah suatu alat yang digunakan mengukur fenomena alam maupun sosial yang diamati. (Sugiyono, 2013:133). Dalam penelitian ini menggunakan dua instrumen penelitian yaitu skala kepedulian dan pedoman eksperimen. Pertama skala kepedulian social adalah skala Likert, peneliti memilih skala Likert karena yang diukur dalam penelitian ini adalah perilaku kepedulian sosial. Menurut Sugiyono (2013:134) "skala likert digunakan untuk mengukur sikap, pendapat, dan persepsi seseorang atau sekelompok orang tentang fenomena sosial". Mengukur tingkat kepedulian sosial pada siswa maka digunakan alat pengumpul data berupa skala kepedulian sosial diadaptasi dan dikembangkan dari komponen-komponen kepedulian sosial (Gaylin dan Mayeroff dalam Burnside, 1979:10). 


\section{INTELIGENSI: Jurnal Ilmu Pendidikan $2018-1$}

\section{Tabel 1 Kisi-kisi Kepedulian Sosial}

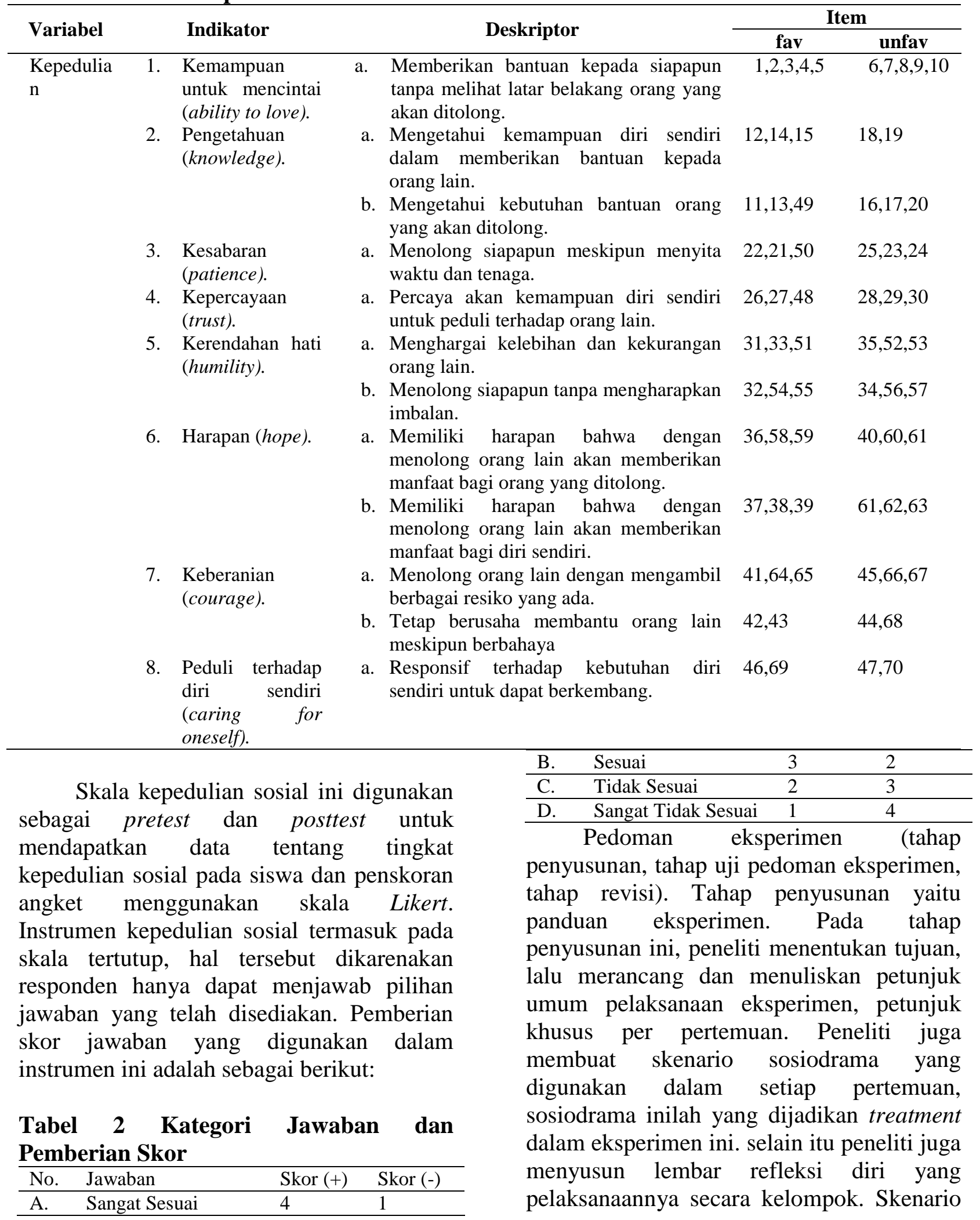




\section{INTELIGENSI: Jurnal Ilmu Pendidikan $\mid$ 2018-1}

sosiodrama yang disusun memuat gambaran perilaku kepedulian sosial. Uji eksperimen yaitu tahap dimana pemberian saran oleh guru kelas. Tahap revisi diberikan kepada guru dan diperbaiki pedoman eksperimennya.

Uji coba instrument melalui tahap validasi dan uji reliabilitas. Sedangkan teknik pengumpulan data menganalisis data adalah : mengelompokkan data berdasarkan variabel dari seluruh responden, menyajikan data tiap variabel yang diteliti, melakukan perhitungan untuk menjawab rumusan masalah, dan melakukan perhitungan untuk menguji hipotesis yang telah diajukan. Dalam penelitian ini teknik analisis data yang digunakan adalah statistik inferensial non parametrik merupakan statistik yang tidak menguji parameter populasi, tetapi menguji distribusi yang tidak menuntut terpenuhinya banyaknya asumsi. Metode non parametrik yang digunakan dalam penelitian ini menggunakan uji Wilcoxon yang merupakan uji non-parametrik degan tidak mensyaratkan distribusi data normal yang digunakan untuk mengetahui keefektifan teknik sosiodrama untuk mengurangi perilaku bullying pada kelompok eksperimen. Untuk uji wilcoxon menggunakan bantuan SPSS 16 for windows.

\section{PEMBAHASAN}

Kegiatan utama penelitian ini adalah analisis data yang telah dirumuskan untuk membuktikan hipotesis penelitian. Sebelum melakukan uji Wilcoxon, perlu dilakukan uji normalitas. Uji normalitas digunakan untuk mengetahui apakah populasi data berdistribusi normal atau tidak (Priyatno, 2010:71). Uji normalitas ini digunakan untuk mengukur data berskala ordinal, interval, atau rasio. Uji normalitas merupakan syarat utama sebelum melakukan analisis statistik. Hasil dari uji normalitas ini merupakan syarat penentuan apakah analisis data menggunakan metode statistik parametrik atau non parametrik. Di bawah ini merupakan penjelasan tahap pelaksanaan uji normalitas.

\section{Tabel 3 Hasil Pretest dan Posttest}

\begin{tabular}{lllll}
\hline No. & Subjek & Pretest & Posttest & Beda \\
\hline 1 & SUBJEK 1 & 97 & 216 & 119 \\
2 & SUBJEK 2 & 117 & 201 & 84 \\
3 & SUBJEK 3 & 100 & 206 & 106 \\
4 & SUBJEK 4 & 130 & 224 & 94 \\
5 & SUBJEK 5 & 116 & 209 & 93 \\
6 & SUBJEK 6 & 110 & 214 & 104 \\
7 & SUBJEK 7 & 113 & 208 & 95 \\
8 & SUBJEK 8 & 120 & 173 & 53 \\
9 & SUBJEK 9 & 106 & 206 & 100 \\
10 & SUBJEK 10 & 107 & 209 & 102 \\
11 & SUBJEK 11 & 107 & 219 & 112 \\
12 & SUBJEK 12 & 114 & 196 & 82 \\
13 & SUBJEK 13 & 116 & 195 & 79 \\
14 & SUBJEK 14 & 125 & 220 & 95 \\
15 & SUBJEK 15 & 124 & 189 & 65 \\
16 & SUBJEK 16 & 113 & 208 & 95 \\
17 & SUBJEK 17 & 114 & 190 & 76 \\
18 & SUBJEK 18 & 112 & 212 & 100 \\
19 & SUBJEK 19 & 122 & 198 & 76 \\
20 & SUBJEK 20 & 111 & 216 & 105 \\
21 & SUBJEK 21 & 104 & 209 & 105 \\
22 & SUBJEK 22 & 108 & 216 & 108 \\
23 & SUBJEK 23 & 109 & 217 & 108 \\
24 & SUBJEK 24 & 112 & 210 & 98 \\
25 & SUBJEK 25 & 104 & 195 & 91 \\
26 & SUBJEK 26 & 113 & 220 & 107 \\
27 & SUBJEK 27 & 109 & 168 & 59 \\
28 & SUBJEK 28 & 170 & 201 & 31 \\
29 & SUBJEK 29 & 172 & 207 & 35 \\
30 & SUBJEK 30 & 115 & 201 & 86 \\
\hline Skor & rata-rata & 116,3 & 205 & 88,8
\end{tabular}

Dari tabel 3 dikeahui bahwa jumlah hasil rata-rata pretest kepedulian social sebesar 116,3 dan jumlah rata-rata hasil posttest sebesar 205 dengan rata-rata beda jumlah skor 88,8. Dengan demikian dapat dikatakan bahwa kepedulian social siswa mengalami peningkatan. 


\section{INTELIGENSI: Jurnal Ilmu Pendidikan |2018-1}

Tabel 4 uji normalitas

Tests of Normality

\begin{tabular}{|l|r|r|r|l|l|l|}
\hline \multirow{2}{*}{} & \multicolumn{4}{|l|}{ Kolmogorov-Smirnov $^{\mathrm{a}}$} & \multicolumn{4}{l|}{ Shapiro-Wilk } \\
\cline { 2 - 7 } & Statistic & df & Sig. & Statistic & df & Sig. \\
\hline selisih & .177 & 30 & .017 & .881 & 30 & .003 \\
\hline
\end{tabular}

a. Lilliefors Significance Correction

Dari Tabel 4 Shapiro-Wilk menunjukkan nilai signifikansi lebih kecil dari 0,05 , yaitu 0,003 yang berarti populasi data berdistribusi tidak normal. Setelah diketahui uji normalitas menunjukkan bahwa data berdistribusi tidak normal, maka ditentukan metode analisis statistik menggunakan statistik non-parametrik.

Untuk melihat peningkatan kepedulian sosial pada siswa sebelum dan sesudah diberikan treatment.dilakukan analisis data berdasarka data pada table (table perbandingan pretest posttest) mengguakan uji Wilcoxon dengan menggunakan bantuan spss 16 for windows, sehingga menghasilkan perolehan data sebagai berikut:

Tabel 5 descriptive Statistic

\begin{tabular}{|l|r|r|r|r|r|}
\hline & $\mathrm{N}$ & Mean & $\begin{array}{c}\text { Std. } \\
\text { Deviati } \\
\text { on }\end{array}$ & $\begin{array}{c}\text { Minim } \\
\text { um }\end{array}$ & $\begin{array}{c}\text { Maxim } \\
\text { um }\end{array}$ \\
\hline PRETEST & 30 & 116.33 & 16.506 & 97 & 172 \\
POSTTEST & 30 & 205.10 & 13.121 & 168 & 224 \\
\hline
\end{tabular}

Tabel 6 Wilcoxon Signed Rank Test

\begin{tabular}{|ll|l|l|l|}
\hline & $\mathrm{N}$ & $\begin{array}{l}\text { Mean } \\
\text { Rank }\end{array}$ & $\begin{array}{l}\text { Sum of } \\
\text { Ranks }\end{array}$ \\
\hline $\begin{array}{l}\text { POSTTEST } \\
\text { PRETEST }\end{array}$ & $\begin{array}{l}\text { Negative } \\
\text { Ranks } \\
\text { Positive } \\
\text { Ranks } \\
\text { Ties }\end{array}$ & $30^{\mathrm{b}}$ & .00 & .00 \\
& $0^{\mathrm{c}}$ & & \\
& Total & 30 & & \\
\hline
\end{tabular}

a. POSTTEST < PRETEST

b. POSTTEST > PRETEST
Tabel 7 Test Statistic

\begin{tabular}{|l|l|}
\hline & $\begin{array}{l}\text { POSTTEST } \\
\text { PRETEST }\end{array}$ \\
\hline$Z$ & $-4.783^{\mathrm{a}}$ \\
Asymp. Sig. (2-tailed) & .000 \\
\hline
\end{tabular}

a. Based on negative ranks.

b. Wilcoxon Signed Ranks Test

c. POSTTEST $=$ PRETEST

Berdasarkan table 5, 6 dan 7 dapat dielaskan bahwa sebelum pelatihan hasil pretest dari 30 orang peserta kelompok eksperimen menunjukan skor minimal sebesar 97 dan skor maksimal sebesar 172 dengan mean sebesar 116.33 . Setelah mengikuti kegiatan sosiodrama skor posttest peserta menunjukkan nilai minimal sebesar 168 dan skor maksimal sebesar 224 dengan mean sebesar 205.10 Nilai Wilcoxon sebesar (-4.783 ${ }^{\mathrm{a}}$ ) dengan nilai ASYMP.Sig. (2-tailed) sebesar .000 . dengan demikian dapat disimpulkan bahwa terdapat perbedaa tigkat kepedulian sosial siswa antara sebelum dan sesudah sosiodrama pada subjek peneitian.

Hipotesis yang diajukan dalam penelitian ini yaitu: 1) $\mathrm{H}_{1}$ : teknik sosiodrama efektif untuk meningkatkan kepedulian sosial siswa $\mathrm{H}_{0}$ : teknik sosiodrama tidak efektif untuk meningkatkan kepedulian siswa. Untuk menguji hipotesis tersebut dilakukan analisis data berdasarka data pada table (table perbandingan pretest posttest) mengguakan uji Wilcoxon dengan menggunakan bantuan spss 16 for windows. Dari hasil analisis dengan menggunakan uji Wilcoxon diperoleh nilai probability error $(\mathrm{p}=000<$ 0.05, maka $\mathrm{H}_{0}$ ditolak dan $\mathrm{H}_{1}$ diterima. Dengan kata lain, bahwa teknik sosiodrama efektif untuk meningkatkan kepedulian sosial siswa SD. 


\section{INTELIGENSI: Jurnal Ilmu Pendidikan $\mid$ 2018-1}

\section{PENUTUP}

\section{Kesimpulan}

Berdasarkan hasil penelitian dan pembahasan yang diuraikan sebelumnya, maka dapat disimpulkan bahwa, terdapat perbedaan yang signifikan antara tingkat kepedulian sosial siswa sebelum dan sesudah diberikan treatment dan teknik sosiodrama efektif untuk meningkatkan kepedulian sosial siswa.

\section{Saran}

Berdasarkan hasil penelitian eksperimen yang telah dilakukan peneliti, terdapat beberapa saran yang dapat disampaikan, yaitu:

\section{Bagi Guru}

a. Guru dapat membantu siswa untuk meningkatkan kepedulian sosial dengan menggunakan teknik sosiodrama, sehingga siswa dapat meningkatkan kepedulian sosial antar sesama.

b. Guru dalam menerapkan teknik sosiodrama harus mempertimbangkan beberapa hal seperti: kesiapan, kesiapan siswa, ketersediaan waktu, ketersediaan media, memiliki pengetahuan dan ketrampilan mengenai teknik sosiodrama dalam membantu siswa yang kurang peduli terhadap sesama dalam kehidupan sosialnya.

c. Guru dalam menerapkan teknik sosiodrama hendaknya menyesuaikan tema dan topik dengan indikator yang ingin dicapai serta mengangkat cerita-cerita yang menarik agar siswa tertarik untuk memainkan peran dalam sosiodrama.

d. Teknik sosiodrama hendaknya dilengkapi dengan refleksi tentang pelaksanaannya di setiap akhir permainan.
2. Bagi Peneliti Selanjutnya

a. Peneliti selanjutnya bisa menggunakan kelompok kontrol sebagai pembanding. Sehingga hasil yang diperoleh akan lebih sempurna dan bisa memperkuat hasil penelitian.

b. Dalam penelitian ini peningkatan kepedulian sosial dilihat setelah beberapa kali melakukan pelatihan sosiodrama. Diharapkan untuk peneliti selanjutnya dapat melihat peningkatan kepedulian sosial siswa setiap setelah memberikan treatment agar peningkatan kepedulian sosial dapat diketahui presentasenya dari setiap treatment.

c. Hasil penelitian yang diperoleh belum optimal dan diharapkan bagi peneliti selanjutnya untuk dapat memberikan layanan konseling baik secara individu maupun secara kelompok.

\section{DAFTAR RUJUKAN}

Amri, Sofan., dkk. 2011. Implementasi Pendidikan Karakter Dalam

Pembelajaran. Jakarta: PT Prestasi Pustakarya

Budi S, Djoko. 2009. Dasar-Dasar Bimbingan dan Konseling. Malang: Universitas Negeri Malang.

Budiningsih, Dr.C.Asri.2001. pembelajaran Moral. Jakarta: Rieneka Cipta

Burnside, Irene Mortenson, dkk.1979. Psychosocial Caring Throughout The Life Span. (Online) (http://books.google.co.id/books/psych osocial-caring-throughout-the-lifespan/) diakses 13 Oktober 2017 


\section{INTELIGENSI: Jurnal Ilmu Pendidikan | 2018-1}

Hurlock, E.B. 2006. Psikologi Perkembangan: Pendekatan Sepanjang Rentang Kehidupan. Jakarta: Erlangga.

Muthuharoh, Hartinah. 2010. Metode Sosiodrama dan Bermain Peranan (Role Playing Method).(Online) (http://alhafizh84.wordpress.com/210/ 01/16/metode-sosiodrama-danbermain-peranan-role-playingmethod/)diakses 10 Oktober 2017

Romlah, Tatiek. 2006. Teoridan Praktek Bimbingan Kelompok: UM Malang

Santrock, John.W.2 007. Perkembangan Anak: Erlangga

Saptono, M.Pd. 2011. Dimensi - dimensi Pendidikan Karakter. Jakarta: Erlangga

Sugiono. 2011. Metode Penelitian Kuantitatif, Kualitatif, dan $R \& D$. Bandung: Penerbit Alfabeta 